\title{
Patients' perspective on the surgical treatment of hallux valgus
}

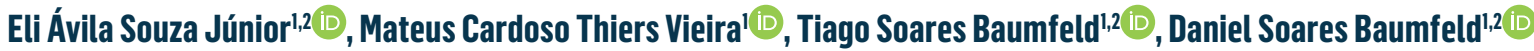 \\ 1. Universidade Federal de Minas Gerais, Belo Horizonte, MG, Brazil. \\ 2. Felício Rocho Hospital, Belo Horizonte, MG, Brazil.
}

\section{Abstract}

Objective: To evaluate patients' perspectives on the risk factors for hallux valgus, and their quality of life before and after surgery.

Methods: This is a cross-sectional, retrospective study, conducted in a tertiary hospital with 50 patients undergoing surgical treatment of hallux valgus. Data were tabulated using three methodological figures: central idea, key expressions and collective subject discourse.

Results: Regarding the risk factors, most of the patients demonstrated knowledge, expressed through central ideas such as: heredity, and wearing inappropriate shoes. In relation to quality of life before surgery, impairment was noted, inferred by central ideas such as: pain and discomfort, restriction in the use of shoes, functional limitation and aesthetic impairment; and regarding postoperative quality of life, most patients expressed satisfaction with the results.

Conclusion: Authentic discourses in the context of a prevalent pathology have expressed, for the first time, the conceptions of risk factors, quality of life before and after hallux valgus surgery.

Level of Evidence V; Therapeutic Study; Expert Opinion.

Keywords: Hallux valgus; Foot deformities; Qualitative research; Bioethics.

\section{Introduction}

Hallux valgus is one of the most common foot diseases requiring orthopedic surgical treatment. The prevalence of hallux valgus in the general population ranges from $21 \%$ to $70 \%$; consequently, 2 million surgeries to correct this deformity are performed in the United States each year ${ }^{(1)}$.

Hallux valgus has different levels of severity, and under certain conditions, it can be considered a serious problem, affecting quality of life. Patient complaints may include difficulty in selecting shoes, limitation in daily activities, toenail disorders, and the occurrence of callus ${ }^{(2,3)}$.

In addition to the severity of the hallux deformity, other factors may affect quality of life of these patients. Hallux valgus treatment mainly aims to correct the deformity and reduce the pain. However, $26 \%$ to $30 \%$ of patients remain dissatisfied even after surgical correction. Thus, understanding other associated factors may provide information on treatment goals beyond the surgical approach alone ${ }^{(4,5)}$.

For Minayo, qualitative research answers particular questions, considering as study subjects people belonging to a group and with a certain social condition, with a universe of meanings, values, beliefs and attitudes. Exploratory research is carried out in an area in which there is little accumulated and systematized knowledge, constituting the first stage of a broader investigation, and is developed when the subject is little explored. Due to its probing nature, it does not present hypotheses, although these may arise during or at the end of the research ${ }^{(6)}$.

In practice, it is clear that not all patients with deformity are aware of the risk factors involved in the genesis of the pathology. Still, it is considered that surgical treatment brings 
great improvement in the quality of life of these patients. This study uses a qualitative approach to evaluate patients' perceptions regarding the risk factors for this prevalent disease and their quality of life before and after surgery.

\section{Methods}

This study was approved by the Institutional Review Board and registered on the Plataforma Brazil database under CAAE (Ethics Evaluation Submission Certificate) number: 15861618.5.0000.5149.

This is a retrospective, exploratory-descriptive study, with a qualitative approach.

The inclusion criteria were patients submitted to hallux valgus surgery in the last seven years who agreed to participate in the study.

The study was conducted from April 1, 2019 to December 1, 2019. Its subjects were 50 patients submitted to surgical treatment for hallux valgus and followed up in a tertiary hospital.

To discover and describe the patients' views concerning the surgical treatment of hallux valgus, within the framework of Social Representations (RS), the method of Collective Subject Discourse (CSD) was used, as it enables a closer examination of the phenomenon under study. CSD is a set of discursive data tabulation procedures used to gain insight into a particular topic. The analytical process was operationalized in several steps: selecting key expressions from each discourse, analogous to the vital tone; identifying the central idea of each key expression in order to synthesize the content; identifying similar or complementary central ideas; and gathering key phrases for the central ideas ${ }^{(7)}$.

Individual interviews were conducted, with three semi-structured questions that addressed: the causes of hallux valgus (bunion), quality of life before surgery, and quality of life after surgery. The interviews were recorded and later transcribed to obtain the results. Data on the patients' age, sex, and time (in years) since surgery were also gathered. Patients were asked to sign an Informed Consent Form (ICF) in advance, in compliance with Resolution 466/12 of the National Health Council, which deals with research involving human beings. Any ethical issues related to this work were guided by the above Resolution, and were brought to the attention of the research subjects prior to signing the ICF.

Based on CSD guidelines, three methodological figures were adopted in this work: Key Expression (KE), Central Idea (CI) and Collective Subject Discourse (CSD). For the data analysis, the order of the steps was strictly followed.

The first step involved carefully reading the transcribed narratives/discourses, to gain a general overview and a better understanding of discursive manifestations.

In the second step, each transcript was read separately from each of the guiding script questions.

In the third step, after reading the content of all the responses to each of the three questions, from each respondent, discourse analysis was used to identify Key Expressions (KE) that reveal the essence of the discourse. These KE were placed in italics. Next, the Central Ideas (Cl) were identified, which accurately summarize the meaning of each of the discourses analyzed and each homogeneous set of KE, and will later form the CSD. In addition to the $\mathrm{Cl}$, the KE can also refer to a methodological figure. This same procedure was performed for all three questions.

The fourth step involved discourse analysis, which separately represented each $\mathrm{Cl}$ with its respective similar or complementary KE.

In the fifth stage, the collective discourse was constructed for each grouping. It was necessary to sequence the KE of each group formed, outlining it with a beginning, middle and end. The KE was linked using grammatical connectors, to maintain cohesion of the discourse.

\section{Results}

In regard to the sample characterization, $96 \%$ of respondents were female and $4 \%$ male. The average age was 51.4 years. The average time since surgery was 4.3 years.

Table 1 shows the central ideas and prevalences found for the first question: what do you think were the causes of the bunion?

The central ideas $(\mathrm{Cl})$, key expressions, and collective subject discourse for the first question are listed below:

Cl: Genetics and Heredity- 50\%

CSD: "The causes were genetic. Both my grandmother and mother have deformed feet (...) I believe the deformities were hereditary in origin, I have many cases of this problem in the family (...) it is likely to be hereditary since my maternal grandmother also has bunions; it makes sense because I've had the deformities since I was young (...)"

Cl: Type of footwear worn - 30\%

CSD: "It is directly related to the type of shoe worn, in my case, frequent use of high heels (...) Tight shoes (...) Continuous use of high heels and closed shoes (...) the most important issue are very closed shoes (...)"

\section{Cl: Don't know -20\%}

CSD: "I don't know what the causes were, I always had it on my left foot (...) I have no idea"

Table 2 shows the central ideas and prevalences found for the second question: How would you describe your quality of life before surgical correction?

Table 1. What do you think were the causes of bunion?

\begin{tabular}{lc} 
Central idea & Prevalence \\
\hline Genetics and heredity & $50 \%$ \\
Type of footwear worn & $30 \%$ \\
\hline I don't know & $20 \%$ \\
\hline
\end{tabular}


The central ideas $(\mathrm{Cl})$, key expressions, and collective subject discourse (CSD) for the second question are listed below:

CI: Pain and discomfort - 50\%

CSD: "Before the surgery I felt a lot of pain and discomfort; my feet used to be swollen, and the bunion was red and painful (...) Pain in every part of the foot: the bunion, the toes, the heel (...) I felt a lot of pain, both in the feet, and in the knees due to walking the wrong way (...) All my shoes used to hurt (...) Before the surgery I only remember the terrible and continuous pain (...)"

\section{Cl: Footwear restriction- 20\%}

CSD: My quality of life was not good because the deformity did not allow the use of certain models of more delicate shoes (...) I always had to select certain types of shoes (...) Before the surgery it was horrible, I could not wear high heels, closed and narrow shoes (...) I had difficulty finding shoes and they got ruined quickly because of walking the wrong way (...)"

Cl: Functional Limitation - 15\%

CSD: "I had a lot of difficulty to practice physical activity (...) The quality of life was very poor, I couldn't walk long distances (...) After taking off my shoes I couldn't put my feet on the floor (...) I used to feel insecure when walking (...)"

Cl: Aesthetic Prejudice - 15\%

CSD: "I was very ashamed, because the middle toe overlapped the great toe (...) Unfavorable aesthetics (...) Median quality of life due to discomfort because of aesthetics; I was ashamed of the swollen and reddish appearance of the bunions (...)"

Table 3 shows the central ideas and prevalences found for the third question: how would you describe your quality of life after surgical correction?

Table 2. How would you describe your quality of life before surgical correction?

\begin{tabular}{lc|}
\hline Central idea & Prevalence \\
\hline Pain and discomfort & $50 \%$ \\
\hline Restriction on the use of footwear & $20 \%$ \\
Functional limitation & $15 \%$ \\
Aesthetic damage & $15 \%$ \\
\hline
\end{tabular}

Table 3. How would you describe your quality of life after surgical correction?

\section{Central idea}

Prevalence

Total improvement

$75 \%$

Partial improvement
The central ideas $(\mathrm{Cl})$, key expressions, and collective subject discourse (CSD) for the third question are listed below:

Cl: Total Improvement - 75\%

CSD: "After the surgery it was a great relief, I don't feel anything today; now, my foot has returned to normal, and I am able to wear any type of shoe (...) It has improved a lot, because now I can wear any shoe, I feel no pain, and besides, my feet have become more beautiful (...) it changed my life; now I can move all my toes easily and without pain (...) Now I wear high heels, I can practice sports normally, such as running, swimming, cycling, weight training (...) Much better; I can wear any kind of shoes, without discomfort, pain or embarrassment (...) It has completely changed my life."

CI: Partial Improvement - 25\%

CSD: "Comparing before and after, there was an improvement; however, the foot has poor mobility; it swells after walking or standing for long periods, and it hurts most of the time (...) I still had to have another surgery to remove the screws (...) Moderate improvement, in the cold I have pain in my foot, something I did not have before the surgery, and it becomes swollen later in the day (...) It improved well, but it could be better if I had the other foot corrected also (...)"

\section{Discussion}

The association of hallux valgus with genetic and hereditary causes is frequently seen in the literature. Coughlin ${ }^{(8)}$ reported a family history in $72 \%$ of patients in his retrospective study, with $94 \%$ of the participants reporting a family history of hallux valgus deformity, and 31 reporting that their mothers also had a bunion. Pique-Vidal et al. ${ }^{(9)}$ and colleagues, in a report of 350 hallux valgus patients, constructed a three-generation pedigree in which $90 \%$ of the participants reported that some relative also has a bunion. In this study, heredity was also consolidated as a relevant central idea concerning the risk factors of hallux valgus. Of the total respondents, 50\% mentioned heredity as a correlated factor in the development of the deformity. In a study by Coughlin and Jones ${ }^{(10)}$ this proportion was even higher, with 86 out of 103 adult patients (84\%) reporting a family history of hallux valgus deformities (parents and grandparents).

A study by Owoeye et al. ${ }^{(11)}$ showed a low prevalence of hallux valgus in a typically barefoot Nigerian population. When the manufacture of fashionable leather shoes far exceeded the manufacture of traditional sandals in the 1970s, the incidence of hallux valgus deformity increased substantially $^{(12)}$. In this study, $30 \%$ of the respondents considered the type of footwear worn to be directly related to the development of the deformity. This finding was consistent with the study by Coughlin and Jones ${ }^{(10)}$ in which only $34 \%$ of patients undergoing surgical correction cited constricting footwear as a cause of their deformity.

The presence of hallux valgus is associated with reduced quality of life for those who suffer from this condition ${ }^{(13)}$. In this study, central ideas correlated with this loss of quality of life were well noted: pain and discomfort, restrictions in the wearing of shoes, functional limitation, and aesthetic impairment. 
Pain is the most important and most commonly reported complaint related to hallux valgus. Thordarson et al. ${ }^{(14)}$ found that body pain scores were consistently poorer for bunion patients compared to the general population. Pain was also the most prevalent central idea (50\%) among the respondents in this study.

Tight, narrow-fitting shoes with a constrictive toe compartment can cause the foot to mold to the shape of the shoe, leading to the formation of hallux valgus, or exacerbating an existing deformity ${ }^{(15)}$. In this study, $20 \%$ of the respondents mentioned the use of tight-fitting shoes use as a central idea for the impaired quality of life. A study by Saro et al. ${ }^{16)}$ showed that unrestricted footwear selection seems to be an important factor for patients' perception of health-related quality of life. Regardless of the degree of correction, patients who were unable to wear their preferred choice of footwear were significantly worse in terms of pain and mental health.

A systematic review by $\mathrm{Nix}$ et al. ${ }^{(17)}$ found that there were biomechanical gait changes in hallux valgus patients. These included reduced peak ankle dorsiflexion and foot supination during walking. Elderly patients with deformity described a less stable gait pattern, with reduced speed and decreased stride length when walking on uneven surfaces. This impairment was also highlighted by $15 \%$ of the participants of this study, inferring functional limitation as a central idea for the impaired quality of life.

Most research on hallux valgus patients has focused on the complications and reducing the deformity, but patients are also equally concerned about the repercussions of the surgery on their daily lives. However, measurements of general health and quality of life regarding foot and ankle surgery have been largely ignored so $\mathrm{far}^{(15)}$. This paper is the first in the Brazilian literature to consider the surgical treatment of hallux valgus in a qualitative, patient-centered approach, with original descriptions of the participants' perceptions of their pathology-related quality of life.

Thordarson et al. ${ }^{(18)}$ found, at 12 months of follow-up, a significant improvement in physical and body function scores in patients who received surgical treatment for hallux valgus. Torkki et al. ${ }^{(19)}$ reported a significant difference in pain levels between surgery and non-surgery groups, at 1 year of follow-up. In this study, the majority of patients expressed satisfaction with the surgical treatment. Thordarson et al. ${ }^{(20)}$ report that the patients outcome was not influenced by the degree of deformity, the amount of correction, or the type of surgery performed.

Ferrari and colleagues assessed evidence from randomized trials involving surgery to correct hallux valgus. They found that the number of patients who remained dissatisfied at follow-up was around $25-33 \%$ of cases, although the hallux valgus angle and pain had improved ${ }^{(21)}$. In this study, dissatisfaction was also evidenced. This can be elucidated by the passage: "Comparing before and after, there was an improvement; however, the foot has poor mobility; it swells after walking or long standing for long periods, and it hurts most of the time".

\section{Conclusion}

This qualitative approach evidenced, in an unprecedented way, that most patients have some knowledge of the main risk factors for the occurrence of hallux valgus. It was observed that the quality of life of patients with this disease is impaired, and postoperatively, satisfaction with the results was observed in the majority of the respondents.

Authors' contributions: Each author contributed individually and significantly to the development of this article: EASJ *(https://orcid.org/OOOO-OOO25054-874X) conceived and planned the activities that led to the study, wrote the article, participated in the review process, approved the final version; MCTV *(https://orcid.org/0000-0001-5405-1901) interpreted study results, participated in the review process; DSB *(https://orcid.org/0000-0001-5404-2132) participated in the review process, approved the final version; TSB *(https://orcid.org/0000-0001-9244-5194) participated in the review process, approved the final version. ${ }^{*}$ ORCID (Open Researcher and Contributor ID) (iD).

\section{References}

1. Coughlin MJ, Thompson FM. The high price of high-fashion footwear. Instr Course Lect. 1995;44:371-7.

2. D'Arcangelo PR, Landorf KB, Munteanu SE, Zammit GV, Menz HB. Radiographic correlates of hallux valgus severity in older people. J Foot Ankle Res. 2010;3:20.

3. Nix S, Smith M, Vicenzino B. Prevalence of hallux valgus in the general population: a systematic review and meta-analysis. J Foot Ankle Res. 2010;3:21.
4. Chong A, Nazarian N, Chandrananth J, Tacey M, Shepherd D, Tran P. Surgery for the correction of hallux valgus: minimum fiveyear results with a validated patient-reported outcome tool and regression analysis. Bone Joint J. 2015;97(2):208-14.

5. Lambers Heerspink FO, Verburg $H$, Reininga IH, van Raaij TM. Chevron versus Mitchell osteotomy in hallux valgus surgery: a comparative study. J Foot Ankle Surg. 2015;54(3):361-4.

6. Minayo MCS (org). Social research: theory, method and creativity. Petrópolis: Voices; 1994. 
7. Lefévre F, Lefévre AMC, Teixeira JJV. The collective subject discourse: a methodological approach in qualitative research. Caxias do Sul: EDUCS; 2005

8. Coughlin MJ. Roger A. Mann Award. Juvenile hallux valgus: etiology and treatment. Foot Ankle Int. 1995;16(11):682-97.

9. Pique-Vidal C, Sole MT, Antich J. Hallux valgus inheritance: pedigree research in 350 patients with bunion deformity. J Foot Ankle Surg. 2007;46(3):149-54.

10. Coughlin MJ, Jones CP: Hallux valgus: demographics, etiology, and radiographic assessment. Foot Ankle Int. 2007;28(7):759-77.

11. Owoeye BA, Akinbo SR, Aiyegbusi AL, Ogunsola MO. Prevalence of hallux valgus among youth population in Lagos, Nigeria. Niger Postgrad Med J. 2011;18(1):51-5.

12. Kato T, Watanabe S. The etiology of hallux valgus in Japan. Clin Orthop Relat Res. 1981;(157):78-81.

13. López DL, Callejo González L, Losa Iglesias ME, Canosa JL, Sanz DR, Lobo CC, et al. Quality of life impact related to foot health in a sample of older people with hallux valgus. Aging Dis. 2016;7(1): 45-52.

14. Thordarson DB, Ebramzadeh E, Rudicel SA, Baxter A. Ageadjusted baseline data for women with hallux valgus undergoing corrective surgery. J Bone Joint Surg Am. 2005;87(1):66-75.
15. Parker J, Nester CJ, Long AF, Barrie J. The problem with measuring patient perceptions of outcome with existing outcome measures in foot and ankle surgery. Foot Ankle Int. 2003;24(1):56-60.

16. Saro C, Jensen I, Lindgren U, Felländer-Tsai L. Quality-of-Life Outcome after Hallux Valgus Surgery. Qual Life Res. 2007; 16(5):731-8.

17. Nix SE, Vicenzino BT, Collins NJ, Smith MD. Gait parameters associated with hallux valgus: a systematic review. J Foot Ankle Res. 2013;6(1):9.

18. Thordarson DB, Rudicel SA, Ebramzadeh E, Gill LH. Outcome study of hallux valgus surgery-an AOFAS multi-center study. Foot Ankle Int. 2001;22(12):956-9.

19. Torkki M, Malmivaara A, Seitsalo S, Hoikka V, Laippala P, Paavolainen P. Surgery vs orthosis vs watchful waiting for hallux valgus: a randomized controlled trial. JAMA. 2001;285(19):2474-80.

20. Thordarson D, Ebramzadeh E, Moorthy M, Lee J, Rudicel S. Correlation of hallux valgus surgical outcome with AOFAS forefoot score and radiological parameters. Foot Ankle Int. 2005; 26(2):122-7.

21. Ferrari J, Higgins JP, Williams RL. Interventions for treating hallux valgus (abductovalgus) and bunions. Cochrane Database Syst Rev. 2004;(1):CD000964. 